\title{
Association of ADHD symptoms, depression and suicidal behaviors with anxiety in Chinese medical college students
}

\author{
Yanmei Shen ${ }^{1,2,3 \dagger}$, Yaru Zhang ${ }^{1,2 \dagger}$, Bella Siu Man Chan ${ }^{3}$, Fanchao Meng ${ }^{1,2}$, Tingyu Yang ${ }^{1,2}$, Xuerong Luo ${ }^{1,2^{*}}$ and \\ Chunxiang Huang ${ }^{1,2^{*}}$
}

\begin{abstract}
Background: Anxiety is one of the most common psychiatric disorder and imposes a great burden on both the individual and the society. Previous studies indicate a high comorbidity of anxiety disorders and Attention Deficit Hyperactivity Disorder (ADHD). However, few studies have examined the comorbidity of anxiety and ADHD among medical college students in mainland China. This study aimed to examine the prevalence of anxiety and the associated risk factor of anxiety disorder as well as to explore the association between ADHD symptoms, depression, suicidal behaviors and anxiety.
\end{abstract}

Methods: A cross-sectional design was employed among 4882 medical college students who were recruited and enrolled with convenience sampling. Self-reported demographic information and clinical characteristics were collected online on a computer or through a social media app named Wechat.

Results: The prevalence of anxiety in this study was $19.9 \%$. Students with anxiety were more likely to have a poor relationship with parents, be of Han nationality, have smoking or drinking habits, have an extensive physical disorder history and have engaged in suicidal behaviors. The independent risk factors for anxiety were: smoking, physical disorder history, suicidal ideations, suicide attempts, inattention and hyperactivity. Significant associations were observed between anxiety and depression, inattention, hyperactivity, suicide plans and suicide attempts.

Conclusions: Nearly one in five medical students suffered from anxiety. The findings of this study indicate the importance of addressing both anxiety and ADHD symptoms in order to better promote mental health and the wellbeing of medical students as well as reduce suicidal behaviors.

Keywords: Anxiety, ADHD, Suicidal behaviors, Risk factors, Medical college students

\section{Background}

Anxiety is one of the most common psychiatric disorder and inflicts a great burden on the individual and the society [1]. Anxiety disorder encompasses a class of maladies that include Generalized Anxiety Disorder,

\footnotetext{
* Correspondence: luoxuerong@csu.edu.cn; xyhcx@csu.edu.cn

${ }^{\dagger}$ Yanmei Shen and Yaru Zhang contributed equally to this work.

${ }^{1}$ Department of Psychiatry, The Second Xiangya Hospital, Central South University, Changsha 410011, Hunan, China

Full list of author information is available at the end of the article
}

Panic Disorder and Social Phobia. These disorders are all characterized by excessive fear, anxiety and related behavioral disturbances [2]. The adverse effects of anxiety disorders could result in low life satisfaction for individuals [3] and a productivity loss for society [4].

At the beginning of the twenty-first century (in February, 2001 and April, 2003), the US National Comorbidity Survey Replication (NCS-R) reported that $28 \%$ of individuals with anxiety disorders would live with the disorder for their lifetimes [5]. Baumeister and Harter reported

C C The Author(s). 2020 Open Access This article is licensed under a Creative Commons Attribution 4.0 International License, which permits use, sharing, adaptation, distribution and reproduction in any medium or format, as long as you give appropriate credit to the original author(s) and the source, provide a link to the Creative Commons licence, and indicate if changes were made. The images or other third party material in this article are included in the article's Creative Commons licence, unless indicated otherwise in a credit line to the material. If material is not included in the article's Creative Commons licence and your intended use is not permitted by statutory regulation or exceeds the permitted use, you will need to obtain permission directly from the copyright holder. To view a copy of this licence, visit http://creativecommons.org/licenses/by/4.0/. The Creative Commons Public Domain Dedication waiver (http://creativecommons.org/publicdomain/zero/1.0/) applies to the data made available in this article, unless otherwise stated in a credit line to the data. 
that the 12-month prevalence of anxiety varied from 5.6 to $18.1 \%$ [6]. Bayram \& Bilgel found that higher rates of anxiety were observed among college students, particularly medical students, due to the tremendous pressures of their studies [7]. The prevalence rate reminded high for this specific group of population worldwide [8-10]. According to a study conducted by Zeng et al., the prevalence of anxiety among nursing students in Chinese vocational colleges was41.7\% [11], and the prevalence of anxiety among Chinese medical students was 47.3\% [12]. Alvi et al. suggested that high academic stress in medical schools as well as the extended contact with suffering patients may have an influence on the mental health of medical students [13]. Conversely, the anxiety symptoms of medical students may also generate negative influences on their professional performance with patients, for example, they may have less enthusiasm and compassion in caring for patients [14]. Therefore, studies examining anxiety disorders among medical students is of clinical significance for it may generate findings that could help students to improve their academic performance and achieve occupational success, as well as reduce the social burden of anxiety and its related costs.

Anxiety and depression are the most common comorbidity among mental health disorders $[15,16]$. Approximately $85 \%$ of individuals with depression have a comorbid anxiety disorder. Similarly, up to $90 \%$ of individuals with anxiety also experience depression [17]. Anxiety and depression are also common psychological problems among medical students [18, 19]. A crosssectional study from a medical school in Ethiopia showed that that 30.1 and $51.3 \%$ of medical students suffered from anxiety and depression, while $21.2 \%$ of them had a comorbidity of anxiety and depression [20]. Although the prevalence of depression and anxiety is remarkably high among Chinese medical students [21], few studies examined the co-morbidity of the two disorders in this population. Quite a few theories have suggested that depression has been found to increase the risk of suicide [22, 23]. However, there has been disagreement as to whether comorbid anxiety symptoms or anxiety disorders among depressed individuals puts those individuals at risk for suicide. A longitudinal study of data from the Netherlands Mental Health Survey shows that after controlling for a wide range of mental conditions, comorbid anxiety and depression increased the risk of suicide attempts [24]. Other studies pointed out that several but not all anxiety disorders (e.g. GAD) were risk factors for suicidal behaviors in the general population $[25,26]$.

Some studies $[27,28]$ indicate a high comorbidity of anxiety disorders and Attention Deficit Hyperactivity Disorder (ADHD). For instance, Pliszka et al. [29] reported that approximately among $25 \%$ of children with
ADHD highly comorbid with anxiety disorders, the high comorbidity might result from the overlap of symptoms that characterize the two disorders. Further, some research suggested that the underlying neurobiological pathologies of ADHD and anxiety might contribute to their comorbidity. Specifically, a reduction of hippocampal and prefrontal cortex dopamine gating were observed be related to amygdala-based anxiety in children with ADHD [30]. However, that precise nature of the pertinent pathologies remains unclear.

Several studies have examined the prevalence of anxiety disorders and their associations with ADHD, depression and suicidal behaviors among Chinese children/adolescents [31-33]. However, as previously mentioned, to our knowledge, very few examined the comorbidity of anxiety and ADHD among adults in mainland China. Therefore, the aims of this study were: (1) to examine the prevalence and associated risk factors of anxiety disorders among medical college students in mainland China, and (2) to explore the association between ADHD symptoms, depression, suicidal behaviors and anxiety.

\section{Methods \\ Participants}

A total of 5004 medical college students were invited by a cross-sectional design between January and March of 2018. Convenience sampling selected four classes with 165 medical students at Changsha Health Vocational College; 50 classes with 4759 students at Yiyang Medical College, and; two classes with 80 students at Hunan University of Chinese Medicine. Changsha Health Vocational College and Yiyang Medical College provide threeyear undergraduate programs. As a comprehensive medical university, the Hunan University of Chinese Medicine provides a four-year undergraduate medical program.

College instructors were trained how to direct students to fill the scales. All of the participants were informed that they could choose to fill the questionnaires out either online or through a widely used social media app (WeChat, Tencent Inc., China). All of the participants were informed of their rights to either participate or decline to participate or withdraw at any time. One hundred and ten students declined to participate, and 12 were excluded due to incomplete or missing data in their questionnaires. A total of 4882 participants were enrolled in the study. The study protocol was approved by the Ethics Committee of the Second Xiangya Hospital at Central South University in Changsha, China. All enrolled students signed an official written consent form that had been approved by the Ethics Committee.

\section{Clinical measures}

The socio-demographic data included gender, community, single child or child with siblings, good relationship 
with mother and father, smoking, alcohol use, nationality, family income, parents' education levels, mental disorder history, physical disorder history, family history of mental disorders, handedness, age and body mass index (BMI).

The 20-item Self-Rating Anxiety Scale (SAS) and the Self-Rating Depression Scale (SDS) [34, 35] were employed to measure anxiety and depression symptoms over the previous seven days. The SAS and SDS are widely used selfrating scales and are reported to have good psychometric properties in Chinese populations [36, 37]. Participants were regarded as having anxiety disorders and depression when their total scores exceeded 50 on the SAS and 53 on the SDS [38]. Participants with anxiety were assigned to the anxiety group and participants without anxiety were assigned to the control group.

Suicidal behaviors consisted of suicidal ideations, suicide plans and suicide attempts [39]. Suicidal ideations referred to passive thoughts of wishing for death. Suicide plans involved making plans or preparations for a suicide attempt. Suicide attempts were defined as potentially self-injuring actions that individuals engaged in with an intention to die [39, 40]. The questions asked about suicidal ideations, suicide plans and suicide attempts included: "Have you ever had any thoughts of committing suicide? Have you ever made a suicide plan? Have you ever tried committing suicide?" If an affirmative answer was given to the questions regarding suicide attempts, further questions were asked about the frequency and methods of suicide attempts.

The 18-item World Health Organization (WHO) Adult ADHD Self-report Scale v 1.1 Symptom Checklist (ASRS) was employed to assess current ADHD symptoms. The measure has been proven to have strong psychometric properties for discerning ADHD in a representative sample (Kessler et al., 2007). The ASRS scale consisted of two subscales: a 9-item inattention subscale (ASRSA) and a 9-item hyperactivity-impulsivity subscale (ASRSH). Each item was rated on a five-point Likert scale: 0 for never, 1 for rarely, 2 for sometimes, 3 for often, and 4 for very often. The total score for each subscale (ASRSA and ASRSH) ranged from 0 to 36. Individuals with scores of 17 or higher on either subscale were considered as positive for that subscale [41]. The Chinese version of the ASRS was proved to have a satisfactory psychometric property in [42].

\section{Data analysis}

The Kolmogorov-Smirnov one-sample test was utilized to examine the normal distribution of continuous data. BMI, age, SDS, and SAS did not fit the normal distribution. Therefore, a non-parameter Mann-Whitney U test was utilized to compare the differences between the anxiety and control groups. A chi-squared test was employed to analyze the categorical variables. Multivariate logistic regression analyses were employed for variables showing a statistical trend $(P<0.1)$ to identify which of those variables were independently correlated with anxiety. Relationships between the variables were measured with Spearman product moment correlation coefficients. In addition, a stepwise multiple regression analysis was utilized to investigate the relationships between SAS and variables showing a statistical trend $(P<0.1)$. All statistical analyses were calculated with SPSS (Version 22.0; IBM, Inc., Chicago, Illinois), with the significance level set at 0.05 .

\section{Results}

The prevalence of anxiety among the participants in this study was $19.9 \%$ (972/4882). There were no significant differences between participants with and without anxiety for BMI, gender, single child, community, family income, right-handedness, parents' education level, mental disorder history, and family history of mental disorder $(P>0.05$, Table 1$)$. Participants with anxiety were significantly younger $(18.6 \pm 1.1)$ than participants without anxiety $(18.8 \pm 1.1)(P<0.001$, Table 1$)$. In addition, as demonstrated by Table 1 , participants with anxiety were more likely to have a poor relationship with mother or father; be of Han nationality; smoke or drink alcohol; have a physical disorder history, and have had suicidal ideations, planned suicides, or made suicide attempts $(P<0.05)$.

Table 2 shows that participants with anxiety scored significantly higher on the ASRS attention subscale, ASRS hyperactivity subscale, ASRS total scale and $\operatorname{SDS}(p<$ 0.001 ), with an effect size ranging from -0.35 to -0.64 .

The variables of physical disorder history (OR: 1.429; 95\% CI: $1.056-1.934 ; P=0.021$ ), suicide plans (OR: 1.481; 95\% CI,:1.081-2.028; $P=0.014)$, suicide attempts (OR:1.748; 95\% CI: 1.327-2.304; $P<0.001$ ), ASRSA (OR: 1.558; 95\% CI: $1.286-1.887 ; P<0.001)$, ASRSH (OR: 2.871; 95\% CI: 2.178-3.784; $P<0.001$ ), and depression (OR:10.552; 95\% CI: 8.804-12.646; $P<0.001$ ) remained significant after adjusting for confounders in the multivariate logistic regression analysis (Table 3 ).

In addition, a Pearson correlation analysis among participants with anxiety $(\mathrm{SAS}>50)$ showed significant correlations between the SAS total score and the following parameters: good relationship with father $(r=-0.109, \mathrm{df}=$ 972, $p=0.001)$; depression $(r=-0.427, \mathrm{df}=972, p<0.001)$; suicidal ideations $(r=0.144, \quad \mathrm{df}=972, \quad p<0.001)$; suicide plans $(r=0.183, \mathrm{df}=972, p<0.001)$, and; suicide attempts $(r=$ 0.170, $\mathrm{df}=972, p<0.001), \operatorname{ASRSA}(r=0.183, \mathrm{df}=972, p<$ $0.001)$, and $\operatorname{ASRSH}(r=0.337, \mathrm{df}=972, p<0.001)$. All significant differences passed the Bonferroni corrections (Bonferroni corrected $p<0.05 / 12=0.0042$; all $p \leq 0.001$ ). Finally, the stepwise regression showed significant associations between the SAS score and SDS (beta $=0.365, \mathrm{t}=12.582$, 
Table 1 Demographics and clinical characteristics between Anxiety and control groups

\begin{tabular}{|c|c|c|c|c|c|c|c|}
\hline \multirow{2}{*}{$\begin{array}{l}\text { Variable } \\
\text { Age (years), mean (SD) }\end{array}$} & \multicolumn{2}{|c|}{ control $n=3910$} & \multicolumn{2}{|c|}{ Anxiety $n=972$} & \multirow{2}{*}{$\frac{x^{2} / Z}{-4.739}$} & \multirow{2}{*}{$\frac{p}{0.000^{* * *}}$} & \multirow[t]{2}{*}{$\mathrm{OR}(95 \% \mathrm{Cl})$} \\
\hline & \multicolumn{2}{|c|}{$18.8(1.1)$} & \multicolumn{2}{|c|}{$18.6(1.1)$} & & & \\
\hline BMI $\left(\mathrm{kg} \mathrm{m}^{-2}\right)$, mean (SD) & \multicolumn{2}{|c|}{$20.1(2.4)$} & \multicolumn{2}{|c|}{$20.1(2.6)$} & -0.586 & 0.558 & \\
\hline \multicolumn{8}{|l|}{ Gender } \\
\hline Males, n (\%) & 431 & $11.00 \%$ & 106 & $10.90 \%$ & 0.011 & 0.916 & $1.012(0.808-1.268)$ \\
\hline Females, n (\%) & 3479 & $89.00 \%$ & 866 & $89.10 \%$ & & & \\
\hline Single child, n (\%) & 991 & $25.30 \%$ & 258 & $26.50 \%$ & 0.587 & 0.444 & $1.064(0.907-1.248)$ \\
\hline \multicolumn{8}{|l|}{ Community } \\
\hline Rural & 2820 & $72.10 \%$ & 700 & $72.00 \%$ & 0.004 & 0.947 & $1.005(0.860-1.176)$ \\
\hline Urban & 1090 & $27.90 \%$ & 272 & $28.00 \%$ & & & \\
\hline Good relationship with mother, n (\%) & 3811 & $97.50 \%$ & 912 & $93.80 \%$ & 32.752 & $0.000^{* * *}$ & $0.395(0.284-0.549)$ \\
\hline Good relationship with father, $\mathrm{n}(\%)$ & 3747 & $95.80 \%$ & 887 & $91.30 \%$ & 33.808 & $0.000^{* * *}$ & $0.454(0.346-0.596)$ \\
\hline \multicolumn{8}{|l|}{ Nationality } \\
\hline Others & 517 & $13.20 \%$ & 105 & $10.80 \%$ & 4.101 & $0.043^{*}$ & $1.258(1.007-1.572)$ \\
\hline Han & 3393 & $86.80 \%$ & 867 & $89.20 \%$ & & & \\
\hline Smoking, n (\%) & 134 & $3.40 \%$ & 78 & $8.00 \%$ & 39.614 & $0.000^{* * *}$ & $2.459(1.842-3.281)$ \\
\hline Alcohol, n (\%) & 580 & $14.80 \%$ & 217 & $22.30 \%$ & 31.982 & $0.000^{* * *}$ & $1.650(1.385-1.965)$ \\
\hline \multicolumn{8}{|l|}{ Family income /year (yuan) } \\
\hline Less than $30,000, n(\%)$ & 1624 & $41.50 \%$ & 431 & $44.30 \%$ & 3.601 & 0.308 & \\
\hline $30,000 \sim 50,000, n(\%)$ & 1336 & $34.20 \%$ & 328 & $33.70 \%$ & & & \\
\hline $50,000 \sim 70,000, n(\%)$ & 549 & $14.00 \%$ & 119 & $12.20 \%$ & & & \\
\hline More than $70,000, \mathrm{n}(\%)$ & 401 & $10.30 \%$ & 94 & $9.70 \%$ & & & \\
\hline \multicolumn{8}{|l|}{ Father's education level } \\
\hline Junior middle school and below, n (\%) & 2539 & $64.90 \%$ & 619 & $63.70 \%$ & 0.701 & 0.704 & \\
\hline High School or Technical School, n (\%) & 1005 & $25.70 \%$ & 255 & $26.20 \%$ & & & \\
\hline College or University and above, n (\%) & 366 & $9.40 \%$ & 98 & $10.10 \%$ & & & \\
\hline \multicolumn{8}{|l|}{ Mother's education level } \\
\hline Junior middle school and below, n (\%) & 2865 & $73.30 \%$ & 691 & $71.10 \%$ & 1.89 & 0.389 & \\
\hline High School or Technical School, n (\%) & 811 & $20.70 \%$ & 219 & $22.50 \%$ & & & \\
\hline College or University and above, $\mathrm{n}(\%)$ & 234 & $6.00 \%$ & 62 & $6.40 \%$ & & & \\
\hline Right-handedness, n (\%) & 3370 & $86.20 \%$ & 855 & $88.00 \%$ & 2.103 & 0.147 & $1.171(0.946-1.450)$ \\
\hline Physical disorder history, n (\%) & 224 & $5.70 \%$ & 102 & $10.50 \%$ & 28.363 & $0.000^{* * *}$ & $1.929(1.509-2.466)$ \\
\hline Mental disorder history, n (\%) & 27 & $0.70 \%$ & 11 & $1.10 \%$ & 1.962 & 0.161 & $1.646(0.814-3.330)$ \\
\hline Family history of mental disorder, n (\%) & 77 & $2.00 \%$ & 17 & $1.70 \%$ & 0.2 & 0.655 & $0.886(0.522-1.505)$ \\
\hline Suicidal ideation, n (\%) & 829 & $21.20 \%$ & 460 & $47.30 \%$ & 273.388 & $0.000^{* * *}$ & $3.339(2.881-3.869)$ \\
\hline Suicide plans, n (\%) & 193 & $4.90 \%$ & 178 & $18.30 \%$ & 198.377 & $0.000^{* * *}$ & $4.318(3.473-5.367)$ \\
\hline Suicide attempts, n (\%) & 380 & $9.70 \%$ & 302 & $31.10 \%$ & 295.294 & $0.000^{* * *}$ & $4.187(3.525-4.974)$ \\
\hline
\end{tabular}

Note: ${ }^{*} p<0.05 ;{ }^{* * *} p<0.001$

$p<0.001)$; ASRSH $\quad($ beta $=0.295, \quad \mathrm{t}=8.434, \quad p<0.001)$, ASRSA (beta $=-0.097, \mathrm{t}=-2.767, p=0.006$ ); suicide plans (beta $=0.078, \mathrm{t}=2.713, p=0.007$ ) and good relationship with father (beta $=-0.057, \mathrm{t}=-2.011, p=0.045)$.

\section{Discussion}

Our study showed that the prevalence of anxiety disorders was $19.9 \%$ among medical college students in
Hunan province, China, which is similar to the prevalence of anxiety disorders for medical students in the United States (20.3\%) [43], but lower than that of medical students in western countries (27.5\%) [10] and Australia (45.1\%) [9], higher than the prevalence of medical students reported in another report in China (14.1\%) [8]. In addition, results of this study is significantly higher than the global prevalence for anxiety disorders 
Table 2 ADHD and SDS scores in Anxiety and control groups

\begin{tabular}{|c|c|c|c|c|c|c|c|c|}
\hline Variable & control $n=$ & 3910 & Anxie & 972 & $x^{2} / Z$ & $p$ & $\mathrm{OR}(95 \% \mathrm{Cl})$ & Effect size \\
\hline ASRSA, mean (SD) & $12.2(4.9)$ & & 15.8( & & -19.235 & $0.000^{* * *}$ & & -0.35 \\
\hline ASRSA $\geq 17$ & 727 & $18.60 \%$ & 451 & $46.40 \%$ & 328.773 & $0.000^{* * *}$ & $3.790(3.263-4.402)$ & \\
\hline ASRSH, mean (SD) & $9.0(4.3)$ & & 13.2( & & -23.668 & $0.000^{* * *}$ & & -0.43 \\
\hline ASRSH $\geq 17$ & 142 & $3.60 \%$ & 228 & $23.50 \%$ & 436.817 & $0.000^{* * *}$ & $8.132(6.501-10.171)$ & \\
\hline ASRST, mean (SD) & $21.3(8.3)$ & & 29.0 & & -23.444 & $0.000^{* * *}$ & & -0.42 \\
\hline ASRST $\geq 34$ & 767 & $19.60 \%$ & 494 & $50.80 \%$ & 395.724 & $0.000^{* * *}$ & $4.235(3.651-4.913)$ & \\
\hline SDS, mean (SD) & $44.6(8.7)$ & & 57.9( & & -36.322 & $0.000^{* * *}$ & & -0.64 \\
\hline$S D S>53$ & 794 & $20.30 \%$ & 768 & $79.00 \%$ & 1233.043 & $0.000^{* * *}$ & 14.774 (12.428-17.563) & \\
\hline
\end{tabular}

Note: ASRS Adult ADHD Self-Report Scale, ASRSA Adult ADHD Self-Report Scale-Inattention subscale, ASRSH Adult ADHD Self-Report Scale-Hyperactivity subscale, ASRST Adult ADHD Self-Report Scale-Hyperactivity total score, SDS Self-Rating Depression Scale, ${ }^{* * *} p<0.001$

among general population [44]. There could be several reasons for this higher prevalence. Firstly, mental health problems are reported to be common among college students due to the stress and pressure of striving to succeed academically and having to make postgraduation plans [45]. Moreover, data from different countries showed a widespread prevalence of anxiety among undergraduate medical students [12, 19, 46-48]. Some studies suggested that this may in part stem from a lack of leisure time [48] during their medical education. In addition, the intense doctor-patient relationship might have adversely influenced students' attitudes and led them to feel pessimistic about their future careers [49], especially given that so many conflicts between doctors and patients have been reported in China in recent years [50-53]. Another explanation for the prevalence of anxiety among medical students in this study could be the high proportion of female participants $(89.0 \%)$ - previous studies have shown that females were more prone to suffer from anxiety disorders than males
[54, 55]. In addition, our study found that students with Han nationality have higher levels of anxiety compared to students with other nationalities. Several reasons might contribute to this phenomenon. On the one hand, China has promulgated preferential policies for minorities, which was developed to support the development of minorities in economy, medical treatment, education, as well as other aspects [56]. For instance,, minorities have the advantage to obtain additional scores on the college entrance examination [57]. On the other hand, a large proportion of minorities in China engages in religious beliefs, in which they are reported to have a positive influence in increasing personal happiness and satisfaction [58]. In addition, Gonçalves et al. suggested that medical students with religious beliefs may relieve their anxiety symptoms in college life through religious support [59].

Anxiety disorders were found to be highly comorbid with ADHD in this study (50.8\%), which is consistent with previous evidence [60, 61]. Schatz and Rostain [62]

Table 3 Multivariate analysis for variables associated with anxiety among medical students

\begin{tabular}{|c|c|c|c|c|c|c|c|c|}
\hline \multirow[b]{2}{*}{ Variable } & \multirow[t]{2}{*}{ B } & \multirow[t]{2}{*}{ S.E. } & \multirow[t]{2}{*}{ Wald } & \multirow[t]{2}{*}{$d f$} & \multirow[t]{2}{*}{ Sig. } & \multirow[t]{2}{*}{$\operatorname{Exp}(B)$} & \multicolumn{2}{|c|}{ 95\% C.I.for EXP(B) } \\
\hline & & & & & & & Lower & Upper \\
\hline Good relationship with mother (yes) & -.299 & .237 & 1.592 & 1 & .207 & .742 & .466 & 1.180 \\
\hline Good relationship with father (yes) & -.116 & .197 & .345 & 1 & .557 & .891 & .605 & 1.311 \\
\hline Han & .247 & .136 & 3.302 & 1 & .069 & 1.280 & .981 & 1.670 \\
\hline Smoking (yes) & .404 & .207 & 3.795 & 1 & .051 & 1.497 & .998 & 2.247 \\
\hline Drinking (yes) & .084 & .119 & .500 & 1 & .480 & 1.088 & .861 & 1.375 \\
\hline Physical disorder history (yes) & .357 & .154 & 5.364 & 1 & $021^{*}$ & 1.429 & 1.056 & 1.934 \\
\hline Suicidal ideation (yes) & .193 & .117 & 2.721 & 1 & .099 & 1.213 & .964 & 1.526 \\
\hline Suicide plans (yes) & .393 & .160 & 5.991 & 1 & $.014^{*}$ & 1.481 & 1.081 & 2.028 \\
\hline Suicide attempts (yes) & .559 & .141 & 15.738 & 1 & $.000^{* * *}$ & 1.748 & 1.327 & 2.304 \\
\hline ASRSA (yes) & .443 & .098 & 20.605 & 1 & $.000^{* * *}$ & 1.558 & 1.286 & 1.887 \\
\hline ASRSH (yes) & 1.055 & .141 & 56.032 & 1 & $.000^{* * *}$ & 2.871 & 2.178 & 3.784 \\
\hline Depression (yes) & 2.356 & .092 & 650.467 & 1 & $.000^{* * *}$ & 10.552 & 8.804 & 12.646 \\
\hline
\end{tabular}


suggested that the deficits of early cognitive regulatory among individuals with ADHD may result in a failure to follow social norms and problems with peer relationships. This can in return result in emotional dysregulation, which characterizes anxiety disorders. One study suggested that the strong association between ADHD symptoms and anxiety symptoms might be explained by the similar brain structure pathologies that characterize the two disorders. For example, Levy [30] suggested that the nucleus accumbens is one of the crucial dopamine systems, so impairment to it would cause dysfunction in the three main dopaminergic circuits: the mesolimbic, mesocortical, and nigrostriatal circuits. In addition, they reported that dysfunction in the mesolimbic circuit might be related to the abnormal regulation of anxiety, while dysfunction in the mesocortical circuit might be related to attention deficits, and a poor nigrostriatal circuit might contribute to hyperactivity and emotional disturbances [30]. Nigg and Casey [63] assumed that ADHD symptoms may be involved in the cognitive control and affective responses. These authors suggested that deficits in various brain regions (e.g., the amygdala, the prefrontal cortex, the cerebellum) were associated with impulsive behavior or dysregulatory psychopathology, especially among individuals with ADHD. More studies are needed to explore the underlying pathomechanism that characterizes the association between anxiety and ADHD symptoms.

This study found that both inattention and hyperactivity symptoms were independently associated with anxiety symptoms and that hyperactivity symptoms had a higher OR than inattention symptoms. It is pertinent to note that previous research has assumed there are two possible distinct subtypes of ADHD -Attention Deficit Disorder without hyperactivity (ADD/WO) and Attention Deficit Disorder with hyperactivity (ADD/H). Children with ADD/ WO were more likely to exhibit emotional disorders such as depression and anxiety, but demonstrated a lesser likelihood of serious behavioral problems than children with $\mathrm{ADD} / \mathrm{H}$ [64]. However, some other studies reported inconsistent results with regard to this finding. For example, several studies found no significant difference in the anxiety and depression levels of individuals with the two subtypes of ADHD [65, 66]. The studies further found that individuals with the combined type of ADHA (ADHD/COM) had more severe symptoms of internalizing than the other subtypes [67].

Our study demonstrated a remarkably high correlation between anxiety and depression, which is consistent with previous evidence $[68,69]$. There are several generally accepted explanations for the co-occurrence of anxiety and depression. The similarity between some symptoms of anxiety and depression offers one explanation. For example, both conditions are characterized by sleeping problems, restlessness and fatigue. Second, anxiety and depression might share common etiological factors. A high negative affectivity or emotionality is one latent risk factor for both conditions that is highly likely to contribute to their comorbidity [70, 71]. Third, twins' studies reveal that genes likely account for the comorbidity [72]. Fourth, maladaptive cognition and information processing errors related to negative experiences of social events are associated with both anxiety and depression [73]. Finally, it has been suggested that the neural circuitry dysfunction involved in the emotional regulation of perceptions and behaviors exists in individuals with both anxiety and depression [74, 75]. For example, abnormalities in the responses of the amygdala have been observed in individuals with anxiety or mood disorders [75-77].

The findings of this study suggested that individuals with anxiety disorders were more likely to have suicidal behaviors than individuals without anxiety. In fact, some national organizations have listed anxiety disorders as a significant risk factor for suicidal behaviors [78]. One study suggested that it is the negative emotions related to anxiety that lead to suicidal behaviors [79], given that individuals usually attempt to end their lives in order to escape or gain relief from painful emotions [80, 81]. Furthermore, social avoidance, a characteristic feature of anxiety, is reported to lead to social isolation, a low quality of life, and disabilities, all of which might increase the risk of suicide [82-84]. Other studies suggested that an underlying biological pathology might be associated with acute suicidal acts. For example, one study found high corticotrophin releasing hormone levels in anxiety disorders, which might be associated with acute suicidal acts [85]. Finally, very few of the participants with anxiety reported a mental disorder history. This might indicate that they had a stigma towards mental disorders. Previous studies have suggested that medical students with mental health problems avoid seeking professional help because such problems are stigmatized and the students are embarrassed to have them [86, 87]. This might in lead to further deterioration and increase the risk of engaging in suicidal behaviors.

However, there were also some inconsistent findings. For example, a survey [88] revealed that individuals who suffered from panic disorder alone were not at high risk for suicide attempts, and a study done on a sample of outpatients with bipolar disorders showed no apparent association between suicide attempts and anxiety after controlling the mood disorder [89]. Another study inferred that higher levels of anxiety, hypochondriasis, agitation or fear of death might underlying protective factors against suicidality for inpatient groups with major depression disorders [90]. These discrepant findings might be explained by differences in study sample 
populations or sizes, assessment methods, methodologies, or data analyses processes [91]. On the other hand, as anxiety disorders consist of a spectrum of disorders, the types and severity levels of anxiety disorders should also be taken into consideration. For example, a metaanalysis of anxiety disorders showed that every type of anxiety disorder, excluding Obsessive-Compulsive Disorder, increases the risk of suicidal behaviors [84]. Further, patients with moderate or more severe anxiety symptoms were over three times the risk of having suicidality [92]. Further research is needed to investigate the underlying pathology between anxiety and suicide.

Several limitations to this study must be acknowledged. Firstly, as a large proportion of the participants are females, it might not representall medical students in China. Results obtained in the study are more relevant to female. The reason for the high proportion of females might be related to the following reasons. On one hand, the proportion of females in medical school in China is much higher than males (female: male $=7: 3$ ) [93]. On the other hand, this study utilized convenience sampling, therefore, classes including higher percentage of male students might not be included in the invited population. Future studies should have a balanced sample of males and females to increase the studies' representativeness. Secondly, as the measurement tool used in this study was self-reported assessment scales, a bias may have resulted from participants' stigma towards mental health conditions [94]. Thirdly, an absence of priori analysis is a limitation, so in future, researchers should conduct a priori analysis before conducting studies similar to the current study. Finally, as a cross-sectional study was employed for this study, its findings were insufficient to draw any conclusions about causal relationships between anxiety and other variables. Longitudinal designs are needed to explore those causal relationships.

\section{Conclusion}

In summary, we found that nearly 1 in 5 medical students suffered from anxiety. Poor relationships with parents, being of Han nationality, smoking or alcohol habits, physical disorder history, depression and suicidal behaviors were associated with anxiety symptoms. Inattention and hyperactivity symptoms were independent risk factors for anxiety. The study revealed strong associations between anxiety symptoms and ADHD symptoms, depression and suicidal behaviors. This points to the importance of addressing ADHD symptoms among students with anxiety. It also highlights the importance of screening medical students for anxiety disorders in order to better promote the mental health and well-being of this population and better prevent suicidal behaviors.

\section{Abbreviations}

DSM-IV: Diagnostic and statistical manual of mental disorders, 4th edition; SDS: Zung's self-rating depression scale; SAS: Self-rating anxiety scale; OR: Odds ratio; BMI: Body mass index; ASRS: Adult ADHD self-report scale; ASRSA: Adult ADHD self-report scale-inattention subscale; ASRSH: Adult ADHD self-report scale-hyperactivity subscale; ASRST: Adult ADHD self-report scale-hyperactivity total score

\section{Acknowledgements}

The authors are very grateful to the participants in this study and school personnel who offered invaluable support.

\section{Authors' contributions}

$X R L, C X H$ and YMS constructed the study design. YRZ and FCM recruited the participants. TYY, BSMC and YMS were involved in statistical analysis. XRL and $\mathrm{CXH}$ were responsible for the critical revision of the manuscript. BSMC, FCM and TYY edited and revised the manuscript. YMS and YRZ prepared and drafted the manuscript. All the authors who contributed to the manuscript gave their approval for its submission to BMC psychiatry. The work presented here has not been published previously and is not being considered for publication elsewhere. The author (s) read and approved the final manuscript.

\section{Funding}

This study was supported by the National Key Research and Development Program of China (No.2017YFC1309900), the National Key Research and Development Program of China (No. 2016YFC1306105) and the Fundamental Research Funds for the Central Universities of Central South University (No.2019zzts818). These institutions had no further role in the study design, the collection and analysis of data, the writing of the report, and the decision to submit the paper for publication.

\section{Availability of data and materials}

The datasets that were generated analyzed for the current study are not publicly available as the author does not have permission to share the data.

\section{Ethics approval and consent to participate}

The research protocol was approved by the Ethics Committee of the Second Xiangya Hospital, Central South University, China. All procedures performed in studies involving human participants were in accordance with the ethical standards of the Institutional Research Committee and with the 1964 Helsinki declaration and its later amendments, or in accordance with comparable ethical standards. All enrolled students signed an official written consent form that had been approved by the Ethics Committee.

Consent for publication

Not Applicable.

\section{Competing interests}

The authors declare that they have no conflict of interest.

\section{Author details}

${ }^{1}$ Department of Psychiatry, The Second Xiangya Hospital, Central South University, Changsha 410011, Hunan, China. ${ }^{2}$ Mental Health Institute of Central South University, China National Clinical Research Center on Mental Disorders (Xiangya), China National Technology Institute on Mental Disorders, Hunan Technology Institute of Psychiatry, Hunan Key Laboratory of Psychiatry and Mental Health, Changsha 410011, Hunan, China. ${ }^{3}$ The Department of Educational and Counselling Psychology, and Special Education, The University of British Columbia, Vancouver, Canada.

Received: 4 October 2019 Accepted: 18 March 2020

Published online: 22 April 2020

\section{References}

1. Lepine JP. The epidemiology of anxiety disorders: prevalence and societal costs. J Clin Psychiatry. 2002;63(Suppl 14):4-8.

2. American Psychiatric Association: Diagnostic and statistical manual of mental disorders (DSM-5 ${ }^{\oplus}$ ): American Psychiatric Pub; 2013. 
3. Mahmoud JS, Staten R, Hall LA, Lennie TA. The relationship among young adult college students' depression, anxiety, stress, demographics, life satisfaction, and coping styles. Issues Ment Health Nurs. 2012;33(3):149-56.

4. Sado M, Takechi S, Inagaki A, Fujisawa D, Koreki A, Mimura M, Yoshimura K. Cost of anxiety disorders in Japan in 2008: a prevalence-based approach. BMC Psychiatry. 2013;13:338.

5. Kessler RC, Merikangas KR, Wang PS. Prevalence, comorbidity, and service utilization for mood disorders in the United States at the beginning of the twenty-first century. Annu Rev Clin Psychol. 2007;3:137-58.

6. Baumeister $\mathrm{H}$, Harter M. Prevalence of mental disorders based on general population surveys. Soc Psychiatry Psychiatr Epidemiol. 2007;42(7):537-46.

7. Bayram N, Bilgel N. The prevalence and socio-demographic correlations of depression, anxiety and stress among a group of university students. Soc Psychiatry Psychiatr Epidemiol. 2008:43(8):667-72.

8. Sun L, Sun L-N, Sun Y-H, Yang L-S, Wu H-Y, Zhang D-D, Cao H-Y, YJTIJoPiM S. Correlations between psychological symptoms and social relationships among medical undergraduates in Anhui Province of China. Int J Psychiatry Med. 2011:42(1):29-47.

9. Casey D, Thomas S, Hocking DR, AJAP K-C. Graduate-entry medical students: older and wiser but not less distressed. Australas Psychiatry. 2016;24(1):88-92.

10. Tian-Ci Quek T, Tam W-S, X Tran B, Zhang M, Zhang Z, Su-Hui Ho C, Rlljoer C-MH, Health P. The Global Prevalence of Anxiety Among Medical Students: A Meta-Analysis. Int J Environmental Res Public Health. 2019;16(15):2735.

11. Zeng Y, Wang G, Xie C, Hu X, Reinhardt JD. Prevalence and correlates of depression, anxiety and symptoms of stress in vocational college nursing students from Sichuan, China: a cross-sectional study. Psychol Health Med. 2019:1-14.

12. Shi M, Liu L, Wang ZY, Wang L. The mediating role of resilience in the relationship between big five personality and anxiety among Chinese medical students: a cross-sectional study. PLoS One. 2015;10(3):e0119916.

13. Alvi T, Assad F, Ramzan M, FAJJCPSP K. Depression, anxiety and their associated factors among medical students. J Coll Physicians Surg Pak. 2010; 20(2):122-6

14. Dyrbye LN, Thomas MR, TDJAm S. Systematic review of depression, anxiety, and other indicators of psychological distress among US and Canadian medical students. Acad Med. 2006;81(4):354-73.

15. Sartorius N, Ustun TB, Lecrubier $Y$, Wittchen HU. Depression comorbid with anxiety: results from the $\mathrm{WHO}$ study on psychological disorders in primary health care. Br J Psychiatry Suppl. 1996;30:38-43.

16. Kessler RC, Gruber M, Hettema JM, Hwang I, Sampson N, Yonkers KA. Comorbid major depression and generalized anxiety disorders in the National Comorbidity Survey follow-up. Psychol Med. 2008;38(3):365-74.

17. Gorman JM. Comorbid depression and anxiety spectrum disorders. Depress Anxiety. 1996;4(4):160-8.

18. van der Walt S, Mabaso W, Davids E, PJSAMJ DV. The burden of depression and anxiety among medical students in South Africa: A cross-sectional survey at the University of Cape Town. SAMJ: S Afr Med J. 2019;110(1):69-76.

19. Hope V, MJMe H. Medical student depression, anxiety and distress outside N orth A merica: a systematic review. Med Educ. 2014;48(10):963-79.

20. Kebede MA, Anbessie B, Glljomhs A. Prevalence and predictors of depression and anxiety among medical students in Addis Ababa. Ethiopia. Int J Ment Health System. 2019;13(1):30.

21. Mao Y, Zhang N, Liu J, Zhu B, He R, XJBme W. A systematic review of depression and anxiety in medical students in China. BMC Med Educ. 2019; 19(1):327.

22. Shaffer D, Gould MS, Fisher P, Trautman P, Moreau D, Kleinman M, Flory M Psychiatric diagnosis in child and adolescent suicide. Arch Gen Psychiatry. 1996;53(4):339-48.

23. Gould MS, Greenberg T, Velting DM, Shaffer D. Youth suicide risk and preventive interventions: a review of the past 10 years. J Am Acad Child Adolesc Psychiatry. 2003;42(4):386-405.

24. Sareen J, Cox BJ, Afifi TO, de Graaf R, Asmundson GJ, ten Have M, Stein MB. Anxiety disorders and risk for suicidal ideation and suicide attempts: a population-based longitudinal study of adults. Arch Gen Psychiatry. 2005; 62(11):1249-57.

25. Cougle JR, Keough ME, Riccardi CJ, Sachs-Ericsson N. Anxiety disorders and suicidality in the National Comorbidity Survey-Replication. J Psychiatr Res. 2009;43(9):825-9.

26. Goodwin RD, Roy-Byrne P. Panic and suicidal ideation and suicide attempts: results from the National Comorbidity Survey. Depress Anxiety. 2006;23(3): 124-32.
27. Das D, Cherbuin N, Butterworth P, Anstey KJ, Easteal S. A population-based study of attention deficit/hyperactivity disorder symptoms and associated impairment in middle-aged adults. PLoS One. 2012;7(2):e31500.

28. Kessler RC, Adler L, Barkley R, Biederman J, Conners CK, Demler O, Faraone SV, Greenhill LL, Howes MJ, Secnik K, et al. The prevalence and correlates of adult ADHD in the United States: results from the National Comorbidity Survey Replication. Am J Psychiatry. 2006;163(4):716-23.

29. Pliszka SR, Carlson CL, Swanson JM. ADHD with comorbid disorders: clinical assessment and management: Guilford press; 1999.

30. Levy F. Synaptic gating and ADHD: a biological theory of comorbidity of ADHD and anxiety. Neuropsychopharmacology. 2004;29(9):1589-96.

31. Liu TL, Yang P, Ko CH, Yen JY, Yen CF. Association between ADHD symptoms and anxiety symptoms in Taiwanese adolescents. J Atten Disord. 2014;18(5):447-55.

32. Shea CKS, Lee MMC, Lai KYC, Luk ESL, Leung PWL. Prevalence of anxiety disorders in Hong Kong Chinese children with ADHD. J Atten Disord. 2018; 22(5):403-13.

33. Xia W, Shen L, Zhang J. Comorbid anxiety and depression in school-aged children with attention deficit hyperactivity disorder (ADHD) and selfreported symptoms of ADHD, anxiety, and depression among parents of school-aged children with and without ADHD. Shanghai Arch Psychiatry. 2015;27(6):356-67.

34. Zung WW. A SELF-RATING DEPRESSION SCALE. Arch Gen Psychiatry. 1964; 12(12):63.

35. Zung WWK. A rating instrument for anxiety disorders. Psychosomatics. 1900; 12(6):371-9.

36. Peng H, Zhang Y, Ji Y, Tang W, Li Q, Yan X, Zhuang Q. Reliability and validity of the Chinese version of self-rating depression scale in rural areas. Shanghai pharma. 2013;14:20-3.

37. Tao M, Gao J. The reliability and validity of the Self-Rating Anxiety Scale Chinese revision version. J Chin Neuropsychiatr Dis. 1994;(5):301-3.

38. Zhang M, Zhang B: [psychiatric rating scale manual]. 1998.

39. Posner K, Oquendo MA, Gould M, Stanley B, Davies M. Columbia classification algorithm of suicide assessment (C-CASA): classification of suicidal events in the FDA's pediatric suicidal risk analysis of antidepressants. Am J Psychiatr. 2007;164(7):1035-43.

40. Joiner TE Jr, Steer RA, Brown G, Beck AT, Pettit JW, Rudd MD. Worst-point suicidal plans: a dimension of suicidality predictive of past suicide attempts and eventual death by suicide. Behav Res Ther. 2003;41(12):1469-80.

41. Kessler RC, Adler L, Ames M, Demler O, Faraone S, Hiripi E, Howes MJ, Jin R, Secnik K, Spencer T. The World Health Organization adult ADHD self-report scale (ASRS): a short screening scale for use in the general population. Psychol Med. 2005;35(2):245.

42. Yeh CB, Gau SF, Kessler RC, Wu YY. Psychometric properties of the Chinese version of the adult ADHD self-report scale. Int J Methods Psychiatr Res. 2008;17(1):45.

43. Mousa OY, Dhamoon MS, Lander S, ASJPo D. The MD blues: underrecognized depression and anxiety in medical trainees. PLoS One. 2016; 11(6):e0156554

44. Baxter AJ, Scott KM, Vos T, Whiteford HA. Global prevalence of anxiety disorders: a systematic review and meta-regression. Psychol Med. 2013;43(5):897-910.

45. Beiter R, Nash R, McCrady M, Rhoades D, Linscomb M, Clarahan M, Sammut S. The prevalence and correlates of depression, anxiety, and stress in a sample of college students. J Affect Disord. 2015;173:90-6.

46. Moutinho IL, Maddalena NC, Roland RK, Lucchetti AL, Tibirica SH, Ezequiel OD, Lucchetti G. Depression, stress and anxiety in medical students: A crosssectional comparison between students from different semesters. Rev Assoc Med Bras (1992). 2017;63(1):21-8.

47. Bunevicius A, Katkute A, Bunevicius R. Symptoms of anxiety and depression in medical students and in humanities students: relationship with big-five personality dimensions and vulnerability to stress. Int J Soc Psychiatry. 2008; 54(6):494-501.

48. Fawzy M, Hamed SA. Prevalence of psychological stress, depression and anxiety among medical students in Egypt. Psychiatry Res. 2017;255:186-94.

49. Wen D, Ma X, Li H, Liu Z, Xian B, Liu Y. Empathy in Chinese medical students: psychometric characteristics and differences by gender and year of medical education. BMC Med Educ. 2013;13:130.

50. Yang T, Zhang H, Shen F, Li JW, Wu MC. Appeal from Chinese doctors to end violence. Lancet. 2013;382(9906):1703-4.

51. Wang $X Q$, Wang $X T$, Zheng JJ. How to end violence against doctors in China. Lancet. 2012;380(9842):647-8. 
52. Wu S, Lin S, Li H, Chai W, Zhang Q, Wu Y, Zhu W. A study on workplace violence and its effect on quality of life among medical professionals in China. Arch Environ Occup Health. 2014;69(2):81-8.

53. Zhao L, Zhang XY, Bai GY, Wang YG. Violence against doctors in China. Lancet. 2014;384(9945):744.

54. Bruce SE, Yonkers KA, Otto MW, Eisen JL, Weisberg RB, Pagano M, Shea MT, Keller MB. Influence of psychiatric comorbidity on recovery and recurrence in generalized anxiety disorder, social phobia, and panic disorder: a 12-year prospective study. Am J Psychiatry. 2005;162(6):1179-87.

55. McLean CP, Asnaani A, Litz BT, Hofmann SG. Gender differences in anxiety disorders: prevalence, course of illness, comorbidity and burden of illness. J Psychiatr Res. 2011;45(8):1027-35.

56. Liu L. New progress of China's national legal system construction-based on the investigation and analysis of the national ethnic legislation practice from 2014 to 2015. Renmin university of China law review. 2016:3:18.

57. Bateer ISI C, Jia ZJ. From Compensatory Fairness to Diversity Advocacy:The Value Reflection and Reconstruction on the Preferential Policy of College Entrance Examination for Ethnic Minorities in China. Jiangsu High Educ. 2019;10:28-34

58. Krägeloh CU, Henning MA, Billington R, SJJAP H. The relationship between quality of life and spirituality, religiousness, and personal beliefs of medical students. Acad Psychiatry. 2015;39(1):85-9.

59. Gonçalves JRL, Jorge AP, Zanetti GC, EdA A, Tótoli RT, GJRdAMB L. Religiousness is associated with lower levels of anxiety, but not depression, in medical and nursing students.Rev Assoc Med Bras. 2018;64(6):537-42.

60. Shekim WO, Asarnow RF, Hess E, Zaucha K, Wheeler N. A clinical and demographic profile of a sample of adults with attention deficit hyperactivity disorder, residual state. Compr Psychiatry. 1990;31(5):416-25.

61. Biederman J, Faraone SV, Spencer T, Wilens T, Norman D, Lapey KA, Mick E, Lehman BK, Doyle A. Patterns of psychiatric comorbidity, cognition, and psychosocial functioning in adults with attention deficit hyperactivity disorder. Am J Psychiatry. 1993;150(12):1792-8.

62. Schatz DB, Rostain AL. ADHD with comorbid anxiety: a review of the current literature. J Atten Disord. 2006;10(2):141-9.

63. Nigg JT, Casey BJ. An integrative theory of attention-deficit/ hyperactivity disorder based on the cognitive and affective neurosciences. Dev Psychopathol. 2005;17(3):785-806.

64. Lahey BB, Carlson CL. Validity of the diagnostic category of attention deficit disorder without hyperactivity: a review of the literature. J Learn Disabil. 1991;24(2):110-20.

65. Power TJ, Costigan TE, Eiraldi RB, Leff SS. Variations in anxiety and depression as a function of ADHD subtypes defined by DSM-IV: do subtype differences exist or not? J Abnorm Child Psychol. 2004;32(1):27-37.

66. Nelson JM, Gregg N. Depression and anxiety among transitioning adolescents and college students with ADHD, dyslexia, or comorbid ADHD/ dyslexia. J Atten Disord. 2012;16(3):244-54

67. Faraone SV, Biederman J, Weber W, Russell RL. Psychiatric, neuropsychological, and psychosocial features of DSM-IV subtypes of attention-deficit/hyperactivity disorder: results from a clinically referred sample. J Am Acad Child Adolesc Psychiatry. 1998;37(2):185-93.

68. Nyer M, Farabaugh A, Fehling K, Soskin D, Holt D, Papakostas Gl, Pedrelli P, Fava M, Pisoni A, Vitolo O. Relationship between sleep disturbance and depression, anxiety, and functioning in college students. Depress Anxiety. 2013;30(9):873-80.

69. Wolk CB, Carper MM, Kendall PC, Olino TM, Marcus SC, Beidas RS. Pathways to anxiety-depression comorbidity: a longitudinal examination of childhood anxiety disorders. Depress and anxiety. 2016;33(10):978-86.

70. Barlow DH. Unraveling the mysteries of anxiety and its disorders from the perspective of emotion theory. Am Psychol. 2000;55(11):1247-63.

71. Clark LA, Watson D. Tripartite model of anxiety and depression: psychometric evidence and taxonomic implications. J Abnorm Psychol. 1991;100(3):316-36.

72. Hudziak JJ, Rudiger LP, Neale MC, Heath AC, Todd RD. A twin study of inattentive, aggressive, and anxious/depressed behaviors. J Am Acad Child Adolesc Psychiatry. 2000;39(4):469-76.

73. Wilson JK, Rapee RM. The interpretation of negative social events in social phobia with versus without comorbid mood disorder. J Anxiety Disord. 2005;19(3):245-74.

74. Phillips ML, Drevets WC, Rauch SL, Lane R. Neurobiology of emotion perception II: implications for major psychiatric disorders. Biol Psychiatry. 2003;54(5):515-28.
75. Thomas KM, Drevets WC, Dahl RE, Ryan ND, Birmaher B, Eccard CH, Axelson D, Whalen PJ, Casey BJ. Amygdala response to fearful faces in anxious and depressed children. Arch Gen Psychiatry. 2001;58(11):1057-63.

76. Drevets WC. Functional neuroimaging studies of depression: the anatomy of melancholia. Annu Rev Med. 1998;49:341-61.

77. Drevets WC. Prefrontal cortical-amygdalar metabolism in major depression. Ann N Y Acad Sci. 1999;877:614-37.

78. Bentley KH, Franklin JC, Ribeiro JD, Kleiman EM, Fox KR, Nock MK. Anxiety and its disorders as risk factors for suicidal thoughts and behaviors: a metaanalytic review. Clin Psychol Rev. 2016;43:30-46.

79. Stein D, Apter A, Ratzoni G, Har-Even D, Avidan G. Association between multiple suicide attempts and negative affects in adolescents. J Am Acad Child Adolesc Psychiatry. 1998;37(5):488-94.

80. Boergers J, Spirito A, Donaldson D. Reasons for adolescent suicide attempts: associations with psychological functioning. J Am Acad Child Adolesc Psychiatry. 1998;37(12):1287-93.

81. Baumeister RF. Suicide as escape from self. Psychol Rev. 1990;97(1):90-113.

82. Massion AO, Warshaw MG, Keller MB. Quality of life and psychiatric morbidity in panic disorder and generalized anxiety disorder. Am J Psychiatry. 1993;150(4):600-7.

83. Olatunji BO, Cisler JM, Tolin DF. Quality of life in the anxiety disorders: a meta-analytic review. Clin Psychol Rev. 2007;27(5):572-81.

84. Kanwar A, Malik S, Prokop L, Sim LA, Feldstein D, Wang Z, Murad MH. The association between anxiety disorders and suicidal behaviors: a systematic review and meta-analysis. Depress Anxiety. 2013;30(10):917-29.

85. Fawcett J, Busch KA, Jacobs D, Kravitz HM, Fogg L. Suicide: a four-pathway clinical-biochemical model. Ann N Y Acad Sci. 1997;836:288-301.

86. Gulliver A, Griffiths KM, Christensen H. Perceived barriers and facilitators to mental health help-seeking in young people: a systematic review. BMC Psychiatry. 2010;10:113.

87. Dahlin ME, Runeson B. Burnout and psychiatric morbidity among medical students entering clinical training: a three year prospective questionnaire and interview-based study. BMC Med Educ. 2007;7:6.

88. Vickers K, McNally RJ. Panic disorder and suicide attempt in the National Comorbidity Survey. J Abnorm Psychol. 2004;113(4):582-91.

89. Leverich GS, Altshuler LL, Frye MA, Suppes T, Keck PE Jr, McElroy SL, Denicoff KD, Obrocea G, Nolen WA, Kupka R, et al. Factors associated with suicide attempts in 648 patients with bipolar disorder in the Stanley Foundation bipolar network. J Clin Psychiatry. 2003;64(5):506-15.

90. Placidi GP, Oquendo MA, Malone KM, Brodsky B, Ellis SP, Mann JJ. Anxiety in major depression: relationship to suicide attempts. Am J Psychiatry. 2000; 157(10):1614-8

91. Li ZZ, Li YM, Lei XY, Zhang D, Liu L, Tang SY, Chen L. Prevalence of suicidal ideation in Chinese college students: a meta-analysis. PLoS One. 2014;9(10): e104368.

92. Diefenbach GJ, Woolley SB, Goethe JW. The association between self-reported anxiety symptoms and suicidality. J Nerv Ment Dis. 2009;197(2):92-7.

93. Zhao W, Yin X, Fan J, Hu J, Li L. Current situation and analysis of bilingual teaching in medical students major in clinical medicine of Dali university. Health Vocational Educ. 2019;23:66.

94. Sartorius N. Stigma and mental health. Lancet. 2007;370(9590):810-1.

\section{Publisher's Note}

Springer Nature remains neutral with regard to jurisdictional claims in published maps and institutional affiliations.

Ready to submit your research? Choose BMC and benefit from:

- fast, convenient online submission

- thorough peer review by experienced researchers in your field

- rapid publication on acceptance

- support for research data, including large and complex data types

- gold Open Access which fosters wider collaboration and increased citations

- maximum visibility for your research: over $100 \mathrm{M}$ website views per year

At $\mathrm{BMC}$, research is always in progress.

Learn more biomedcentral.com/submission 